\title{
Construction of tourism culture system from the perspective of global
}

\author{
tourism \\ Hui-ying CHEN \\ School of Arts and Communications, \\ Wuhan Polytechnic University, Wuhan, Hubei, 430023, China \\ Chenhy0921@qq.com
}

Keywords: global tourism; tourism culture; System Construction

Abstract: With the New Perspective on the concept of Global Tourism, based on the whole industry, the whole element, the whole time and space to construct the tourism culture system from the perspective of the global tourism. The tourism culture system includes three subsystems: Material Culture, institutional culture and Spiritual Culture, which construct a complete whole area tourism culture system.

\section{Concept of tourism culture system from the perspective of global tourism}

The whole industry.Global tourism requires all industries to take part in the tourism industry,and all departments cooperate with each other to make full use of the various attraction resources in the region and meet the needs of visitors in many aspects. Therefore, the tourism culture system should be established with concept of the whole industry. we integrate three elements of tourism material culture, tourism system, behavior culture and tourism spirit culture to realize the coordination and interaction of products, management and ideology tourism destination culture and the development of common prosperity .

The whole element.Global tourism requires the co-ordination of resources in the social area and systematic optimization of relevant industries, facilities and services, resources, legal systems and citizenship so as to realize the organic integration of various tourism industry components. The construction of tourism culture system should embody the concept of the whole element, coordinate cultural resources, construct multi-level tourism material and cultural products, create composite cultural products and create new image of overall products; foster new management concepts and create tourism market civilization Showing the regional institutional culture, the masses enhance the behavior of cultural accomplishment; shaping the characteristics of cultural quality and adventure spirit.

The whole time and space.Through the design of all-weather excursion cultural experience products, the half-day tourist economy can be transformed into an all-day tourist economy, thereby extending the resident time of tourists and enhancing the tourism and cultural experience in different time zones of the same space, thus making the tourists experiences different from others Regional culture of the unique local culture, to achieve the emotional interaction and resonance, planning to local tourism and cultural background as the basis for tourism boutique base, lengthen the all-weather tourism industry chain, to build suitable for play, fit, suitable employment leisure vacation tourism Regional culture. 


\section{Analysis of elements of tourism culture system construction from the perspective of global tourism}

The whole element linkage development, construct multi-level tourism and cultural product system.Tourism in the context of global tourism, tourism is no longer the traditional point - line approach, as tourists demand more and more consumption of tourism products, tourism product development, the single planning and development of tourism products has been unable to meet the tourist needs of consumers. In addition to integration of local characteristics of tourism and cultural elements to create a new tourism and cultural products, but also need to play a tourism development model of the global tourism + model , Combined with the characteristics of convention and exhibition, sports, folk, agriculture, health, education and culture, so that all the elements of the cultural development of linkage, build multi-level tourism and cultural product system.

Cultural integration, to create a series of cultural tourism boutique brand.Global travel requirements in the construction of tourist destinations to be fully applied to all resources, to create tourism attractive elements, and generate and maintain a strong attraction lies in the key characteristics of resources. From the traditional thinking model to create products to jump out, identify the characteristics of resources, with unique resources to build unique cultural brand, you can give full play to the potential of tourism development, can not follow the trend of imitation, based on the highlight of the core culture of the theme, Cultural integration, to create tourism complex cultural boutique brand.

Global marketing, shaping the overall image of regional tourism.In the mode of development of global tourism, the destination is one. The image of tourism promotion is bound to also need integrated marketing. The main form of current tourism and occupation of the tourism market lies in the portrayal and shaping of the overall image of the region. To rely on the image of travel products to spread the spread is determined by its immobile nature, the image of a region to become tourists potential awareness of this area, and thus have a tourist motivation. Although tourism products rely on their own rich cultural resources to develop, but the image of the publicity is also indispensable. In shaping the overall image, we need to achieve global marketing, marketing is no longer a one-sided corporate marketing, but the government, corporate organizations, residents and tourists four-way linkage marketing campaign in the publicity to cover traditional media to emerging Media, shaping the overall image of regional tourism.

\section{The construction of tourism culture system from the perspective of global tourism}

The construction of the material and cultural system.Material culture is superficial and intuitive. It can be directly felt by people. Therefore, based on the concept of global tourism, creating a multi-layered tourism and cultural product, creating a complex tourism and cultural product, and shaping the overall image of regional tourism constitute a material culture Sub-system components. According to the concept of total factor, the tourism products with multi-level tourism products can meet the overall demand in the tourism process and establish a series of tourism products rich in local culture, such as dietary features, architectural features, traffic and cultural features, characteristics of environmental atmosphere, culture Festivals, etc .; secondly promote the overall development of shopping, transportation, infrastructure and service network in the region and build an integrated tourism infrastructure; based on the concept of full time and space, multi-level tourism products are only the means to satisfy people's basic tourism needs Tourism needs, the construction of complex tourism and cultural boutique is a more level of consumption of tourism material and 
cultural, tourists can longitudinally extend tourist spending time in the region, accordingly, we can create a number of complex tourism and cultural boutique.

The construction of institutional and behavioral cultural Systems.Tourism system, behavior culture as a transitional level, it protects, regulates and guides the orderly development of the tourism environment. No matter what kind of tourism product is created, what kind of tourism atmosphere is established, the system and the behavior culture are ultimately served. Therefore, we regard the strengthening of government regulatory system, the reform of management concept and the standardization of market order as well as the improvement of the quality of participants as the three major constructive factors of tourism system and behavior culture. Strengthen the government-led management role and establish a competent Tourism Authority to break the situation of each department's own operation and division of command and management based on the concepts of global tourism, global industry and global development, and establish a tourism market operation background and rely on the government Dominate the new pattern of the development of tourism industry. In the management process, relying on the new concept of green management, establish the concept of green development and ecological protection, and construct a system of green tourist areas. Targeting at intensifying the management of tourist destination markets and using legal means to rectify disorderly markets, the tourism environment can meet international standards.

The construction of the spiritual and culture system. According to the construction concept of the whole industry, it not only needs to build an intuitive material system of the surface layer, a system of transitional support and a system of behavior and culture, but also needs to build a tourism spiritual culture at the core level because the tourist spirit and culture represent the values and pursuits of the whole tourist destination Idea,, with local culture as the main theme, because of the need to guide, dig deep culture as a component of spiritual and cultural sub-system elements. People are more concerned about the real and happy life, the cause is not as busy in the bustling modern city rush workers, work and life are relaxed and enjoy the slow pace. We should regard the leisure and amorous feelings culture as the main theme of the development of spiritual culture of tourism as the basic ideology of tourism promotion and development so that as long as tourists think of traveling, they will think of leisure and enjoyment. On the basis of this, they will dig deep into the features and enhance the cultural taste, Making full use of the natural and cultural cultures of the region and enriching the spiritual and cultural connotations.

\section{Acknowledgement}

This research was financially supported by Wuhan Polytechnic University Research Project called Development Strategy Research on the Transformation and Upgrading of Wuhan Cultural Industry in the era of "Internet + " (number: 2016y10).

\section{Reference}

[1] Lv Junfang. Development of"Intergral Tourism" in China from the Coordinated Perspective of Urban-rural[J].Henan Science , 2014 , 32(1) : 139-142

[2] Yuan Qun."5A+" is an effective way to create a national regional tourism demonstration area [N]. China Tourism newspaper, 2016 - 04 - 29 (2)

[3] Hu Xiaoran. Urban Tourism: whole domain tourism in Dalian [N] under the background of global urbanization. China Tourism newspaper, 2010-12 - 08 (11).

[4] Meng Qiuli, Deng Aimin.Construction of rural tourism product system under the threshold of global tourism[J].Social Scientist,2016,234(10):85-89 